\title{
ANALISIS PROSES DRAWING UNTUK PEMBUATAN PEDAL BRAKE SEPEDA MOTOR RODA TIGA DENGAN SOFTWARE BERBASIS FEM
}

\author{
Norman Iskandar \\ Fakultas Teknik, Departemen Teknik Mesin \\ Universitas Diponegoro \\ Email: norman.undip@gmail.com \\ Deni Fajar Fitriyana \\ Fakultas Teknik, Departemen Teknik Mesin \\ Universitas Diponegoro \\ Email: deniifa89@gmail.com \\ Fuad Arief Raharjo \\ Fakultas Teknik, Departemen Teknik Mesin \\ Universitas Diponegoro \\ Email: ariefraharjo95@gmail.com
}

\begin{abstract}
ABSTRAK
Pedal Brake berfungsi sebagai tempat pijakan kaki pada sistem pengereman pada salah satu produk motor roda tiga di Indonesia. Pembuatan pedal brake menggunakan proses drawing yaitu proses dimana gaya diberikan pada benda kerja agar terdeformasi plastis mengikuti bentuk dari punch dengan kedalaman tertentu. Dalam pembuatan pedal brake menggunakan proses drawing terdapat potensi cacat yang bisa terjadi akibat besarnya gaya serta tingkat kedalaman cetakan. Analisa draw ability dilakukan untuk mengetahui seberapa besar kedalaman proses drawing sebelum benda kerja mengalami kegagalan dengan menghitung nilai Limiting Drawing Ratio (LDR) dan rata-rata plastic strain ratio $\left(\mathrm{R}_{\mathrm{avg}}\right)$. Simulasi dilakukan untuk mengetahui parameter seperti gaya pembentukan, jumlah energi yang digunakan beserta potensi cacat yang timbul pada pedal brake seperti earing dan kegagalan pada saat melakukan proses drawing. Dari hasil perhitungan LDR sebesar 1,028 dan $\mathrm{R}_{\text {avg }}$ sebesar 2,8 untuk jenis material ST-37 menunjukkan bahwa kemampuan draw ability yang rendah dengan gaya pembentukan maksimum sebesar $92,8 \mathrm{kN}$ dan energi yang diserap sebesar 0,69 kJ. Nilai $\mathrm{R}_{\text {avg }}$ sebesar 1,2 untuk jenis material ST-37 cukup besar sehingga potensi terjadinya earing tidak terlalu nampak untuk proses drawing. Perbandingan antara analisa teoritis dan simulasi memiliki error sebesar 6\% sehingga hasil masih dapat dikatakan valid.
\end{abstract}

Kata kunci: drawing, dies, earing, limmiting drawing ratio, rata-rata plastic strain ratio.

\begin{abstract}
Brake pedal serves as a place of footrest on the braking system on one of the three-wheeled motorcycle products in Indonesia. Making the brake pedal using a drawing process is a process whereby the force is applied to the workpiece to be deformed plastic following the shape of the punch with a certain depth. In making brake pedals using the drawing process there are potential defects that can occur due to the size of the force and the depth of the mold. A draw ability analysis was done to find out how much depth of drawing process before work object failed by calculating the value of Limiting Drawing Ratio $(L D R)$ and average plastic strain ratio $\left(R_{\text {avg }}\right)$. The simulation is done to know the parameters such as the forming force, the amount of energy used and the potential defects that arise in the brake pedal such as earing and failure during the drawing process. From the calculation of LDR of 1.028 and Ravg of 2.8 for ST-37 material type shows that low draw ability with a maximum forming force of $92.8 \mathrm{kN}$ and absorbed energy of $0.69 \mathrm{~kJ}$. $R_{\text {avg }}$ value of 1.2 for the type of material ST-37 large enough so that the earning potential is not too visible for the drawing process. The comparison between theoretical and simulated analysis has an error of $6 \%$ so the result can still be said to be valid.
\end{abstract}

Keywords: drawing, dies, earing, limmiting drawing ratio, average plastic strain ratio. 


\section{PENDAHULUAN}

Salah satu BUMN yang bergerak dalam bidang manufaktur dengan berbagai macam produknya baik militer dan non-militer, memiliki fasilitas industri Tempa dan Cor (TC) yang salah satu produk yang dihasilkan yaitu pedal brake seperti terlihat pada gambar 1. Proses pembuatan pedal brake merupakan salah satu aplikasi proses metal forming dengan cara drawing yang mana memerlukan adanya dies.

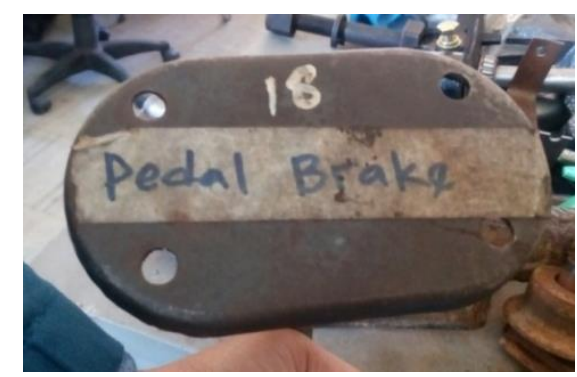

Gambar 1. Pedal Brake Untuk Kendaran Roda Tiga [1]

Proses pembentukan lembaran logam sendiri dapat dikelompokkan menjadi tiga kelompok [2], yaitu:

a. Proses cutting (Pemotongan) adalah proses dimana material di potong sesuai dengan ukuran yang diinginkan agar material tersebut dapat dikerjakan kedalam proses berikutnya.

b. Proses forming (Pembentukan) adalah istilah umum yang dipakai pada proses pembentukan sheet metal untuk mendapatkan kontur yang diinginkan. Proses forming, tidak menghasilkan pengurangan atau penghilangan material seperti yang terjadi pada proses cutting.

c. Proses compression (Penekanan) adalaha salah satu operasi forming yang mana tekanan yang kuat diberikan pada sheet metal untuk menghasilkan tegangan kompresi yang tinggi pada plat untuk menghasilkan deformasi plastis.

Pedal brake merupakan permintaan konsumen yang diaplikasikan pada kendaraan motor roda tiga.Pedal brake berfungsi sebagai tempat pijakan kaki untuk pengereman Motor roda tiga dimana pengereman tersebut mengubah gaya input menjadi gaya output yang besar melalui sistem pengereman. Proses pembuatan pedal brake menggunakan proses drawing. Proses drawing menurut standar Jerman (standar DIN), DIN 8584, didefinisikan sebagai proses pembentukan lembaran logam dengan cara tarik/tekan dimana lembaran logam dibentuk menjadi komponen berongga yang terbuka pada salah satu sisinya (disebut direct drawing), atau merubah sebuah komponen yang memiliki rongga yang terbuka pada salah satu sisinya menjadi komponen dengan rongga yang lebih kecil penampangnya (disebut redrawing) [3,4]

Dalam proses drawing diperlukan pengaturan tentang sejumlah gaya dan energi yang diperlukan serta kedalaman dari proses drawing agar tidak mengalami kecacatan maupun kegagalan proses pembuatan produk.

Dalam proses riilnya, cacat produk masing terjadi. Material yang mengalami cacat pada akhirnya hanya akan menjadi limbah. Untuk mengetahui penyebab cacat pada proses pembuatan pedal brake, bisa dilakukan analisis proses dengan pendekatan software berbasis Metode Elemen Hingga (FEM) serta perhitungan secara analitik.

Metode elemen hingga (FEM) telah menjadi alat yang kuat untuk simulasi proses pembentukan logam dalam beberapa dekade terakhir. Pendekatan dengan metode ini dapat mengurangi waktu yang diperlukan dalam tahap penelitian dan pengembangan serta biaya yang diperlukan untuk produksi [5]. Keakuratan teknik ini sangat bergantung pada objektivitas fisik dari model yang digunakan. Dalam hal ini, model konstitutif menyediakan deskripsi akurat anisotropi plastik dari lembaran logam telah menjadi subyek banyak penelitian. Anisotropi plastik adalah ketergantungan sifat material pada arah pengujian [6].

Dalam proses drawing atau deep drawing, beberapa elemen penting seperti sifat material dan parameter proses serta parameter geometri harus diperhatikan. Sifat material meliputi desnsitas lebaran logam, kekuatan tarik, fracture toughness, koefisien gesek pada logam serta kekuatan tekan. Parameter proses yang harus diperhatikan diantaranya temperature, pelumasan, tekanan punch dan tekanan pada blank-holder. Untuk parameter geometri yang berperan penting adalah bentuk cetakan, material cetakan dan tipe dari proses drawing yang digunakan [3,7].

Radius pada cetakan memiliki peran penting dalam mengatur distribusi ketebalan pada lembaran logam [8]. Geometri dari penekan (punch) merupakan salah satu parameter penting karena punch nose 
berfungsi untuk menipiskan lembaran plat logam dalam proses deep drawing. Ketika radius hidung pada punch kurang dari tiga kali ketebalan plat maka proses akan gagal, dan jika radiusnya lebih besar dari tiga kali tebal palat maka proses penipisan akan berlangsung stabil. Ketebalan plat dan diameter punch akan berpengaruh pada nilai limiting drawing ratio (LDR) dan nilai LDR akan menurun relatif jika diameter punch semakin besar. Ketika celah atau gap antara cetakan penekan/atas dan cetakan bawah kurang dari tebal plat logam benda kerja maka proses akan gagal akibat proses penipisan yang tidak berjalan baik. Proses akan berjalan baik dan stabil jika gap antara cetakan lebih besar dari pada tebal material benda kerja [4].

Beberapa analisis teori telah dikemangkan untuk memprediksi LDR $[9,10]$. Telah banyak upaya yang ddikerahkan dalam beberapa tahun terakhir dalam mengembangkan penggunaan model FEM untuk mengatasi masalah deep drawing dengan lebih baik. Kobayashi [11] telah berhasil mengatasi permasalahan deep drawing dengan konsep hemispherical punch dengan teknik rigid plastic FEM dimana hasil simulasinya memiliki kecocokan yang baik ketika diuji komparasi dengan hasil ekperimen.

Beberapa kegagalan yang terjadi pada proses deep drawing diantaranya adalah fenomena bergelombang (earing), melipat (wrinkling) dan robek (tearing). Earing terjadi karena sketidak seragaman sifat pada material berdasarkan arahnya (anisotropy property) dan gesekan yang tidak cukup. Fenomena ini terjadi pada ujung benda kerja. Wrinkling atau melipat bisa terjadi karena faktor gap antara cetakan atau karena material yang tidak tertarik. Tearing atau sobek terjadi karena cetakan yang memiliki sudut terlalu tajam $[12,13]$.

Simulasi dilakukan dengan menggunakan software berbasis FEM untuk mengetahui potensi kecacatan ketika dilakukan proses drawing. Data yang diperlukan untuk proses simulasi didapatkan dari data material dan data permesinan yang digunakan oleh BUMN tersebut.

Tujuan yang hendak dicapai dalam penelitian ini adalah untuk mengetahui potensi cacat yang mungkin terjadi, mengetahui hasil perhitungan gaya maksimum, jumlah blow, pengaruh LDR terhadap proses drawing serta membandingkan hasil analisis hasil kajian teori maupun simulasi software FEM.

\section{METODOLOGI PENELITIAN}

\subsection{Identifikasi Parameter Yang Mempengaruhi Proses Drawing Pedal Brake}

Proses drawing adalah proses pembentukan (forming) benda kerja dimana benda kerja diberikan gaya atau sejumlah energi agar dapat mengalami deformasi plastis mengikuti bentuk dari punch dengan kedalaman tertentu. Analisis diperlukan agar produk tidak mengalami kecacatan maupun kegagalan selama proses produksi. Adapun hal yang dapat dianalisis diantaranya :

a. Gaya pembentukan untuk drawing.

b. Limitting Drawing Ratio (LDR) untuk menentukan seberapa besar drawability.

c. Rata-rata plastic strain ratio $\left(\mathrm{R}_{\text {avg }}\right)$ untuk menentukan seberapa potensi terjadinya earing.

d. Perhitungan jumlah blow.

Hasil analisis secara teoritis selanjutnya akan dibandingkan dengan hasil analisis dengan metode simulasi dengan menggunakan software berbasis FEM.

\subsection{Proses Simulasi Menggunakan Software Berbasis FEM}

Ada berapa tahapan untuk melakukan simulasi diantaranya tahap tahap pemodelan CAD, tahap preprocessing, running dan postprocessing. Dalam pemodelan CAD dimensi objek dibuat dalam format 3D kemudian diekspor ke dalam software berbasis FEM untuk dilakukan proses simulasi. Tahapan pertama adalah preprocessing yaitu meliputi input geometri yaitu memasukkan gambar hasil pemodelan dalam software CAD. Selanjutnya tahapan input data material, proses meshing dimana digunakan meshing otamatis dalam pengerjaan simulasi ini. Masih dalam tahapan preprocessing selanjutnya adalah konfigurasi beban atau gaya yang bekerja meliputi besar, arah dan mekanisme pembebanan gayanya. Kemudian masuk kedalam tahapan input kondisi batas meliputi batas interaksi antar cetakan dan kondisi lingkungan. Penutup dalam proses ini adalah data base generation untuk memastikan bahwa semua data yang telah diinput benar dan siap untuk tahap running simulation.

Tahap kedua adalah running process dimana proses akan berjalan secara otomatis bergantung dengan setting awal saat preprocessing dan hardware. Pada tahap ini dipantau proses running jika memerlukan tindakan bantu jika terjadi kondisi proses running tidak berjalan lancer. Selain itu grafik hasil simulasi juga harus dipantau untuk memastikan bahwa secara trend proses telah berjalan benar.

Tahpa terakhir adalah tahap post processing dimana pada fase ini adalah fase pengambilan data hasil simulasi yang bisa dijangkau oleh software. Untuk full package software data gaya pembentukan, displacement, temperature, stress-strain, damage terhadap waktu bisa didapatkan. 


\subsection{Analisis Teoritis Proses Pembentukan (Drawing)}

\subsubsection{Perhitungan Gaya Pembentukan (Drawing)}

Analisis secara teoritis untuk menghitung nilai dari gaya pembentukan untuk proses drawing menggunakan persamaan 1 berikut ini [14].

$$
F_{\max }=\pi \mathrm{D}_{\mathrm{p}} \mathrm{T}(\mathrm{UTS})\left[\frac{\mathrm{D}_{\mathrm{o}}}{\mathrm{D}_{\mathrm{p}}}-0.7\right]
$$

Dimana :

$$
\begin{array}{ll}
F_{\max } & =\text { Gaya pembentukan maksimum }(\mathrm{N}) \\
\mathrm{D}_{\mathrm{p}} & =\text { Diameter pembentukan benda kerja }(\mathrm{mm}) \\
\mathrm{D}_{\mathrm{o}} & =\text { Diameter bentangan benda kerja sebelum dibentuk }(\mathrm{mm}) \\
\mathrm{T} & =\text { Tebal Pelat }(\mathrm{mm}) \\
\mathrm{UTS} & =\text { Tegangan Tarik material }\left(\mathrm{N} / \mathrm{mm}^{2}\right) \\
\pi & =\text { Konstanta }(3,14)
\end{array}
$$

\subsubsection{Perhitungan Limiting Drawing Ratio (LDR)}

Analisis secara teoritis untuk menghitung nilai dari Limiting Drawing Ratio (LDR) untuk proses drawing menggunakan persamaan 1 berikut ini [14].

$$
\begin{array}{ll}
\operatorname{LDR}=\frac{D_{o}}{D_{p}} & \\
\text { Dimana : } & \\
\text { LDR } & =\text { Limiting Drawing Ratio } \\
D_{p} & =\text { Diameter pembentukan benda kerja }(\mathrm{mm}) \\
D_{0} & =\text { Diameter bentangan benda kerja sebelum dibentuk }(\mathrm{mm})
\end{array}
$$

\subsubsection{Rata-rata Plastic Strain Ratio (Ravg)}

Plastic strain ratio adalah perbandingan regangan lebar terhadap regangan tinggi dimana nilai tersebut menunjukkan nilai regangan yang sesungguhnya ketika spesimen berada pada kondisi tarik (tension). Data rata-rata plastic strain ratio $\left(\mathrm{R}_{\text {avg }}\right)$ untuk beberapa jenis material sheet metal. Dapat dilihat pada tabel 1.

Tabel 1. Rata-rata plastic strain ratio ( $\left.\mathbf{R}_{\mathrm{avg}}\right)$ untuk beberapa jenis material sheet metal [14]

\begin{tabular}{clc}
\hline No. & \multicolumn{1}{c}{ Material } & \multicolumn{1}{c}{$\boldsymbol{R}_{\text {avg }}$} \\
\hline 1. & Zinc Alloys & $0,4-0,6$ \\
2. & Hot-rolled steel & $0,8-1,0$ \\
3. & Cold-rolled, rimmed steel & $1,0-1,4$ \\
4. & Cold-rolled, aluminium-killed steel & $1,4-1,8$ \\
5. & Aluminum alloys & $0,6-0,8$ \\
6. & Copper dan brass & $0,6-0,9$ \\
7. & Titanium alloys $(\alpha)$ & $3,0-5,0$ \\
8. & Stainless steels & $0,9-1,2$ \\
9. & High-strength, low-alloy steels & $0,9-1,2$ \\
\hline
\end{tabular}

Adapun hubungan antara rata-rata plastic strain ratio dengan LDR dapat dilihat pada gambar 2. Hubungan ini merupakan pernyataan secara grafik yang mengindikasikan apakah material atau bahan masih dapat dilakukan proses drawing atau tidak. 


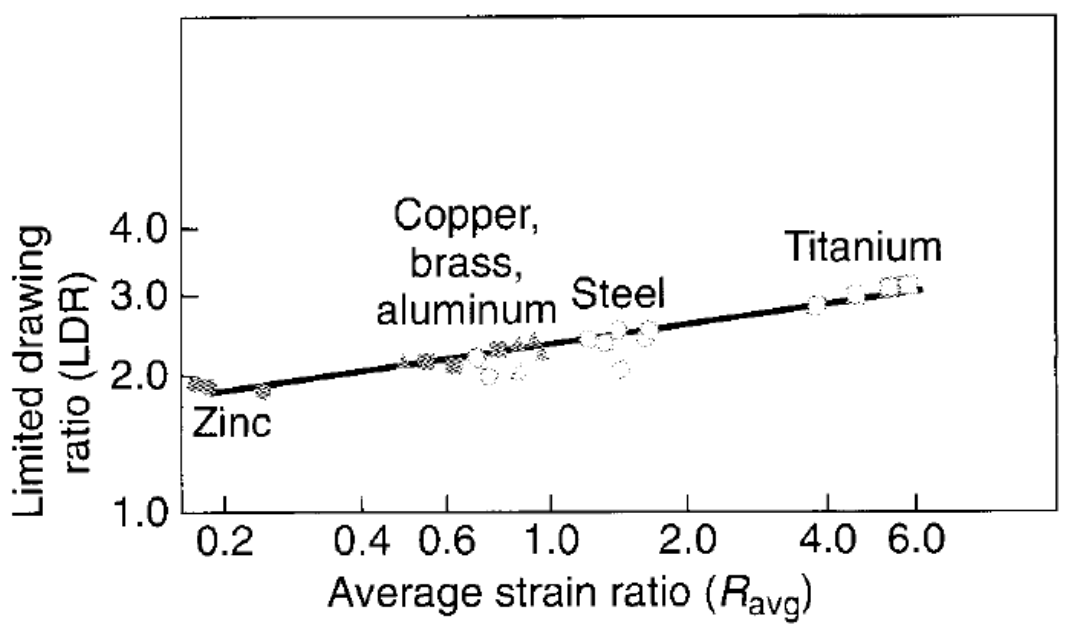

Gambar 2. Hubungan antara LDR dan rata-rata plastic strain ratio [14]

\subsubsection{Perhitungan Jumlah Blow}

Analisis secara teoritis untuk menghitung jumlah blow untuk proses drawing menggunakan persamaan 3 sampai dengan persamaan 7 berikut ini.

a. Kecepatan pembentukan awal $\left(\mathrm{W}_{\mathrm{o}}\right)[1]$

$$
\mathrm{W}_{\mathrm{o}}=\frac{\mathrm{V}}{\mathrm{h}_{\mathrm{o}}}
$$

Dimana :

$\mathrm{W}_{\mathrm{o}} \quad=$ Kecepatan pembentukan awal $(1 / \mathrm{dt})$

$\mathrm{V}=$ Kecepatan mesin $(\mathrm{mm} / \mathrm{dt})$

$\mathrm{h}_{\mathrm{o}} \quad=$ Tinggi bahan kerja awal $(\mathrm{mm})$

b. Kecepatan pembentukan rata-rata $\left(\mathrm{W}_{\mathrm{m}}\right)$ [1]

$\mathrm{W}_{\mathrm{m}}=\mathrm{W}_{\mathrm{o}} \mathrm{K}$

Dimana :

$\mathrm{W}_{\mathrm{m}} \quad=$ Kecepatan pembentukan rata-rata $(1 / \mathrm{dt})$

$\mathrm{W}_{\mathrm{o}} \quad=$ Kecepatan pembentukan awal (1/dt)

$\mathrm{K}=$ Faktor mesin hammer $(0,9)$

c. Tinggi rata-rata pembentukan akhir $\left(\mathrm{h}_{\mathrm{m}}\right)[1]$

$\mathrm{h}_{\mathrm{m}}=\frac{\mathrm{Vol}_{\mathrm{p}}}{\mathrm{A}_{\mathrm{p}}}$

Dimana :

$\mathrm{h}_{\mathrm{m}} \quad$ = Tinggi pembentukan akhir $(\mathrm{mm})$

Vol = Volume benda kerja $\left(\mathrm{mm}^{3}\right)$

$\mathrm{A}_{\mathrm{p}} \quad=$ Luas proyeksi $\left(\mathrm{mm}^{2}\right)$

d. Kerja pembentukan (U) [1]

$\mathrm{U}=\frac{\mathrm{VolQ}_{\mathrm{hm}} \mathrm{Kwa}}{\mu_{\mathrm{f}}}$

Dimana :

$\mathrm{Q}_{\mathrm{hm}} \quad=$ Pembentukan

$\mathrm{U}=$ Kerja pembentukan $(\mathrm{Nmm})$

Kwa $=$ Tahanan pembentukan awal $\left(9 / \mathrm{mm}^{2}\right)$

$\mu_{\mathrm{f}} \quad=$ Efisiensi pembentukan $(0,4)$

Vol $=$ Volume benda kerja $\left(\mathrm{mm}^{3}\right)$ 
e. Jumlah blow [1]

$$
\mathrm{B}=\frac{\mathrm{U}}{\mathrm{E}_{\mathrm{m}}}
$$

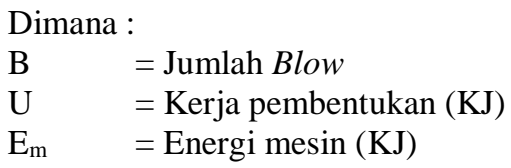

\subsection{Proses Pembentukan Pedal Brake}

Pedal brake terbuat dari material ST-37 dimana material tersebut salah satu jenis material low carbon steel. Desain dari dies drawing pedal brake yang dapat dilihat pada gambar 3. Detail dari spesifikasi bahan baku dan dimensi dies bisa dilihat pada tabel 2.

Tabel 2. Spesifikasi bahan baku dies drawing pedal brake

\begin{tabular}{ll}
\hline \multicolumn{1}{c}{ Data Bahan Baku } & \multicolumn{1}{c}{ Keterangan } \\
\hline Material & $: S T-37$ \\
UTS & $: 435 \mathrm{~N} / \mathrm{mm}^{2}$ \\
Komposisi & $: 0,17 \% \mathrm{C}, 1,4 \% \mathrm{Mn}, 0,045 \%$ P dan $0,045 \% \mathrm{~S}$ \\
Tebal & $: 1,5 \mathrm{~mm}$ \\
Diameter Punch $\left(D_{P}\right)$ & $: 141 \mathrm{~mm}$ \\
Diameter Pedal $\left(D_{o}\right)$ & $: 144 \mathrm{~mm}$ \\
Kedalaman Drawing & $: 9,2 \mathrm{~mm}$ \\
\hline
\end{tabular}

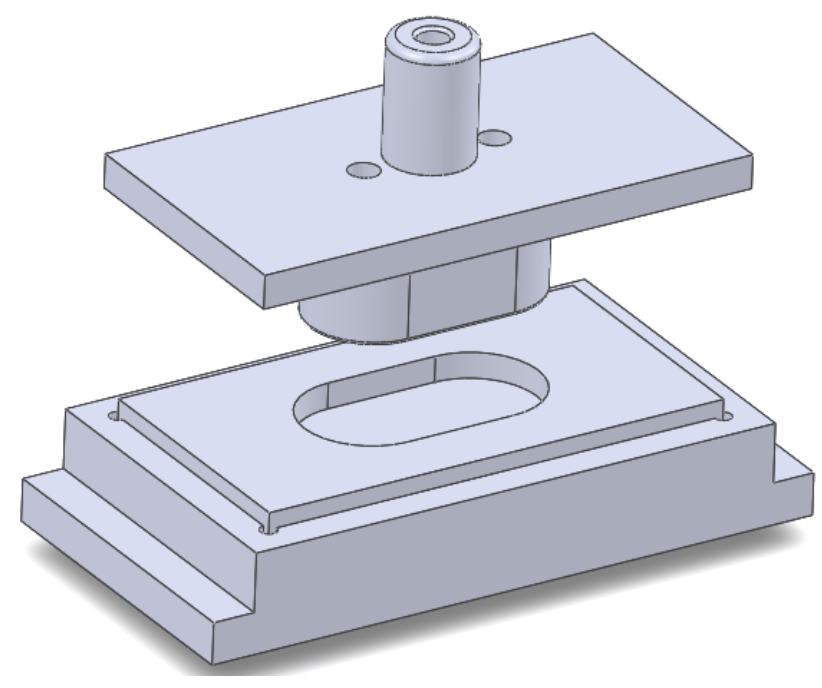

Gambar 3. Dies Drawing Pedal Brake

\section{HASIL DAN PEMBAHASAN}

Pedal brake adalah salah satu komponen pada kendaraan sepeda motor roda tiga yang berfungsi sebagai pijakan kaki untuk sistem pengereman, material yang dipakai untuk membuat pedal brake adalah ST-37 yang berbentuk lembaran. Analisa yang dibahas pada pembahasan meliputi gaya pembentukan, LDR, rata-rata plastic strain ratio $\left(\mathrm{R}_{\mathrm{avg}}\right)$, perhitungan jumlah blow. Hasil perhitungan teoritis dapat dinyatakan sebagai berikut:

\subsection{Perhitungan Gaya Pembentukan}

Dari hasil perhitungan sesuai Persamaan 1 diperoleh gaya pembentukan maksimum $\left(\mathrm{F}_{\max }\right)$ sebesar 92812,9 N yang menyatakan gaya maksimum yang diberikan pada material pedal brake selama proses drawing. 


\subsection{Perhitungan Limiting Drawing Ratio (LDR)}

LDR menunjukkan seberapa besar kemampuan dari benda kerja untuk dilakukan proses drawing (drawability) dari hasil perhitungan sesuai Persamaan 2 diperoleh nilai LDR sebesar 1,028 angka ini menunjukkan bahwa semakin besar nilai LDR maka kemampuan untuk diproses drawing lebih dalam akan semakin besar.

\subsection{Rata-rata Plastic Strain Ratio (Ravg)}

Material yang digunakan sebagai bahan kerja untuk proses pembuatan pedal brake dengan proses drawing dengan menggunakan dies drawing pedal brake adalah material ST 37 merupakan salah satu jenis cold-rolled, rimmed steel sehingga dari tabel 1 diperoleh nilai $R_{\text {avg }}$ sebesar 1,2 . Nilai $R_{\text {avg }}$ menunjukkan seberapa besar potensi terjadinya kecacatan earing. Semakin besar nilai $\mathrm{R}_{\text {avg }}$ maka potensi earing semakin kecil dan sebaliknya, material ST-37 memiliki angka $\mathrm{R}_{\text {avg }}$ yang cukup tinggi sehinggi potensi terjadinya earing relative kecil.

Adapun hubungan antara rata-rata plastic strain ratio dengan LDR untuk material ST 37 dapat dinyatakan dengan gambar 4 dimana $\mathrm{LDR}=2,8$ pada $\mathrm{R}_{\text {avg }}=1,2$ sedangkan pada perhitungan menunjukkan angka 1,028 dimana kemampuan drawability rendah.

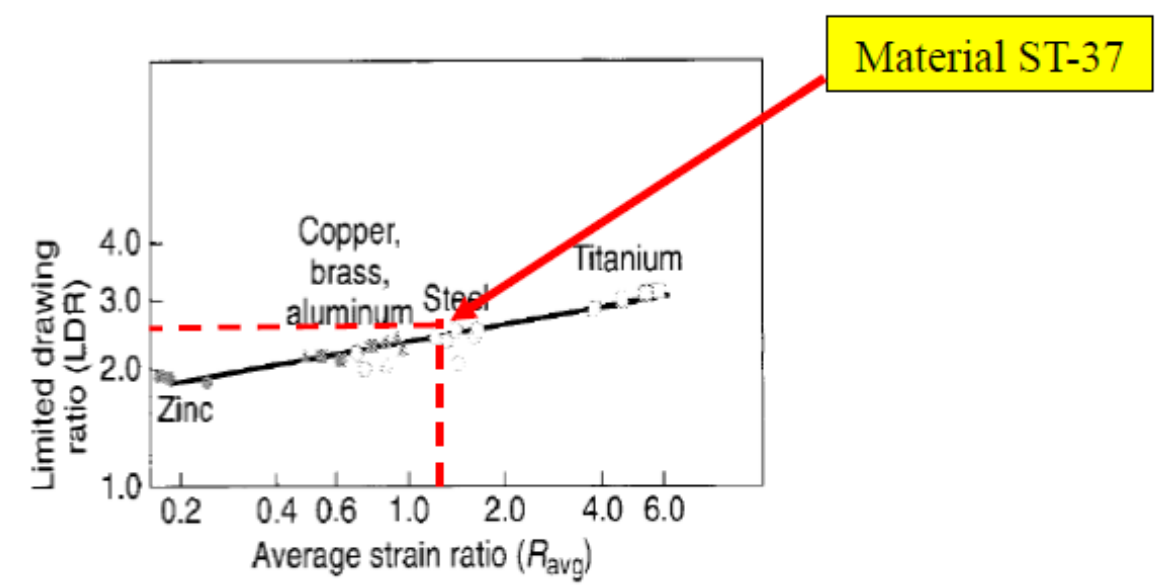

Gambar 4. Hubungan Antara Ldr Dan $R_{a v g}$ Untuk Jenis Material St-37[14]

Potensi kecacatan akibat nilai LDR yang rendah bisa dilihat pada hasil simulasi pada gambar 5 dimana proses drawing yang terlalu dalam menyebabkan terjadinya cacat pada daerah radiusnya.

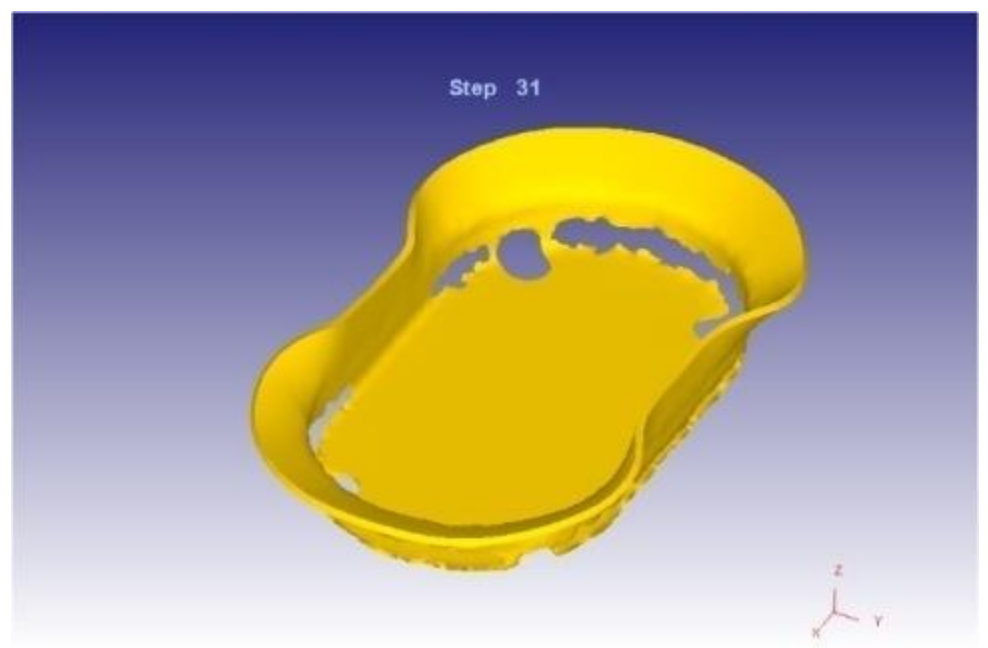

Gambar 5. Potensi Kecacatan Pada Pedak Brake 


\subsection{Perhitungan Jumlah Blow}

Perhitungan jumlah blow dilakukan untuk mengetahui jumlah blow yang dikeluarkan mesin hammer untuk melakukan proses drawing. Terdapat beberapa parameter lain yang diperlukan untuk menghitung jumlah blow dinyatakan dalam tabel 3 berikut :

Tabel 3. Parameter perhitungan jumlah blow [1]

\begin{tabular}{clccc}
\hline No. & \multicolumn{1}{c}{ Perhitungan } & Simbol & Hasil & Satuan \\
\hline 1. & Kecepatan pembentukan awal & $W_{o}$ & 1162 & $1 /$ det \\
2. & Kecepatan pembentukan rata-rata & $W_{m}$ & 1045,8 & $1 /$ det \\
3. & Tinggi rata-rata pembentukan akhir & $h_{m}$ & 4,29 & $\mathrm{~mm}$ \\
4. & Pembentukan & $Q_{h m}$ & 1,052 & - \\
5. & Kerja pembentukan & $U$ & 0,69 & $\mathrm{~kJ}$ \\
6. & Jumlah blow & $B$ & 0,00431 & blow \\
\hline
\end{tabular}

Hasil perhitungan menunjukkan energi yang diperlukan untuk membentuk pedal brake sebesar 0,69 $\mathrm{kJ}$ dengan jumlah blow yang diperlukan sebesar 0,00431 pada proses drawing sampai kedalaman $9 \mathrm{~mm}$.

\subsection{Simulasi Gaya Pembentukan}

Simulasi ini menampilkan perubahan gaya pembentukan selama proses drawing pada pedal brake. Perubahan bentuk pedal brake dalam proses simulasi bisa dilihat pada Gambar 7. Gaya pembentukan dapat dilihat pada Gambar 8, dimana gaya diplot terhadap waktu maupun terhadap langkah (stroke). Hasil simulasi menunjukkan bahwa perubahan gaya yang curam pada waktu antara 0 sampai 0,00137 detik atau pada langkah (stroke) 0 sampai 1,93 mm. Pada langkah (stroke) antara 1,93 mm sampai 3,86 mm terjadi penurunan gaya sedangkan antara langkah (stroke) $3,86 \mathrm{~mm}$ sampai $9,2 \mathrm{~mm}$ relatif mengalami kenaikan gaya pembentukan dimana hasil gaya pembentukan maksimum sebesar $86,5 \mathrm{kN}$ dimana gaya tersebut mendekati hasil perhitungan analitik yaitu $92,8 \mathrm{kN}$.

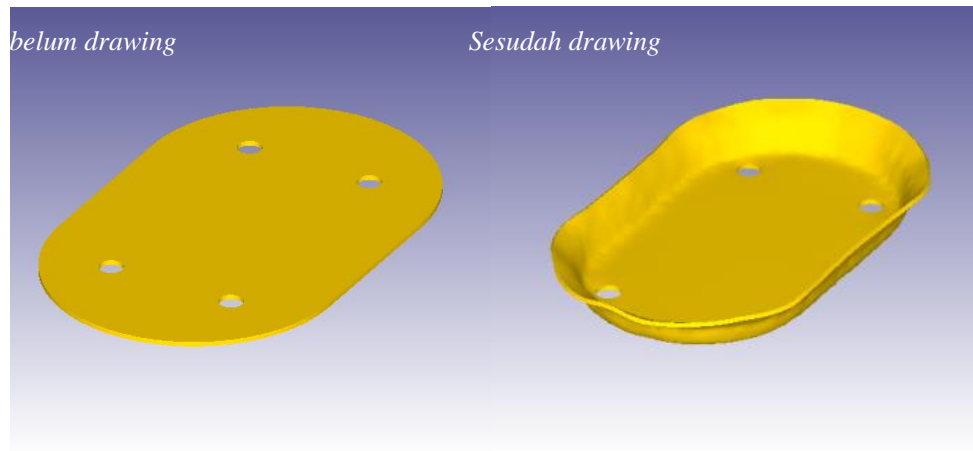

Gambar 7. Simulasi Pedal Brake Sebelum Dan Sesudah Proses Drawing
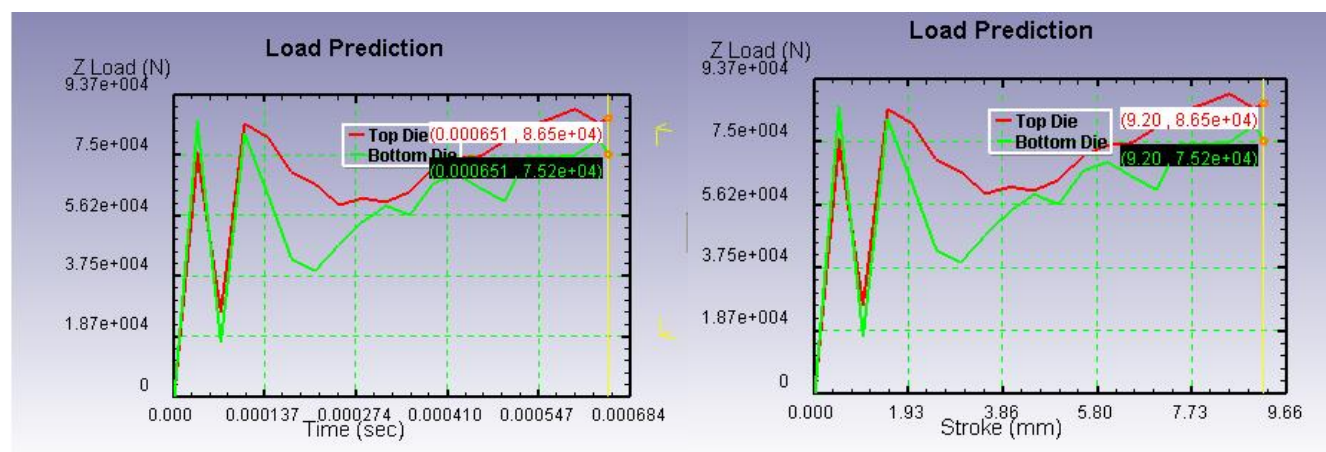

Gambar 8. Hubungan Antara Gaya Terhadap Waktu Dan Gaya Terhadap Stroke Pada Proses Drawing. 


\subsection{Simulasi Energi Pembentukan}

Simulasi energi pembentukan adalah jumlah energi yang dibutuhkan untuk membentuk pedal brake melalui proses drawing. Hasil simulasi dapat dilihat pada Gambar 9. Dari gambar tersebut memperlihatkan bahwa jumlah energi yang dibutuhkan untuk membentuk pedal brake mengalami peningkatan yang relatif proporsional terhadap perubahan waktu dan pertambahan langkah (stroke), energi maksimum berada ketika die atas mencapai titik langkah pada $9.2 \mathrm{~mm}$ dan energi yang dicapai sebesar $0,69 \mathrm{~kJ}$.

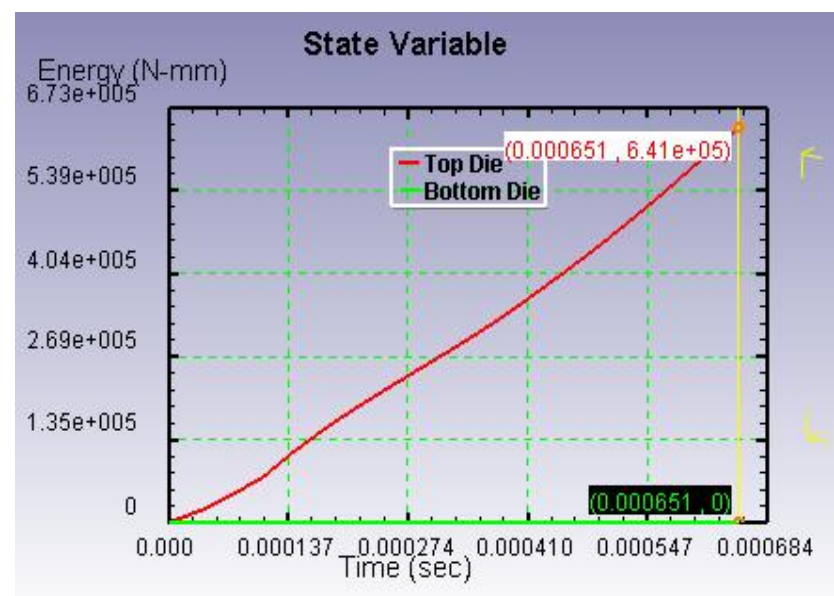

Gambar 9. Kurva Energi Pembentukan Pedal Brake Pada Proses Drawing

\subsection{Simulasi Temperatur Benda Kerja}

Simulasi temperatur benda kerja adalah simulasi dimana perubahan temperatur yang terjadi pada benda kerja dapat ditampilkan dalam bentuk kontur dan kurva terhadap waktu. Perubahan temperatur dapat dilihat pada Gambar 10 dimana temperatur benda kerja mengalami peningkatan sebesar temperatur $62{ }^{\circ} \mathrm{C}$ dalam waktu 0,000137 detik, antara 0,000137 sampai 0,000410 tidak mengalami kenaikan dan mulai naik kembali sampai suhu maksimum sebesar $86,6{ }^{\circ} \mathrm{C}$. Temperatur pembentukan drawing seharusnya berkisar antara $40-60{ }^{\circ} \mathrm{C}$.

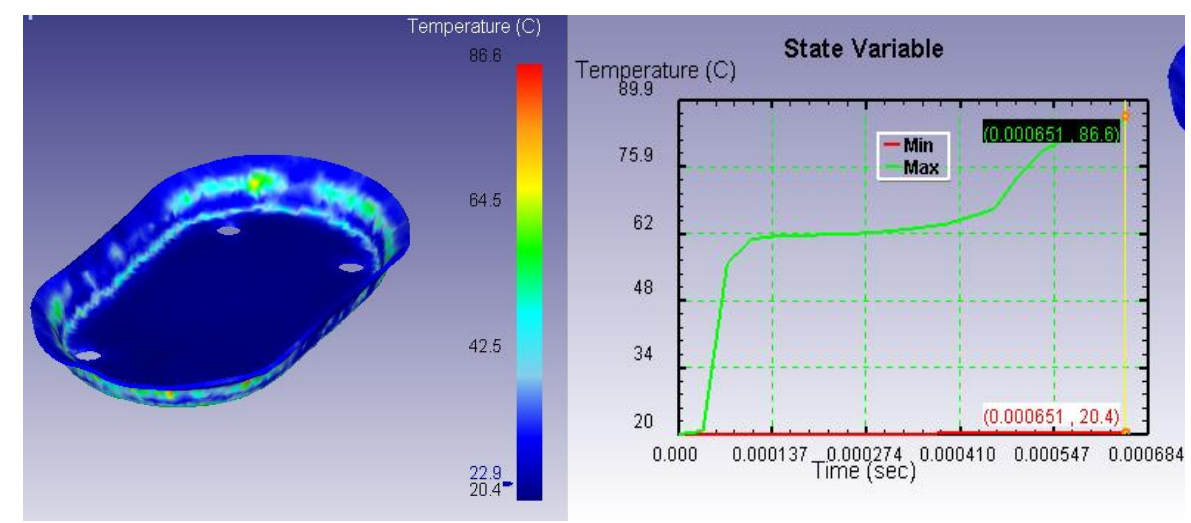

Gambar 10. Simulasi Temperatur Pedal Brake Pada Proses Drawing

\subsection{Simulasi Damage}

Simulasi damage benda kerja adalah simulasi dimana potensi damage pada benda kerja dapat ditampilkan. Pada Gambar 11 menunjukan potensi damage terhadap benda kerja dimana bahwa pada daerah disekitar radius meiliki potensi kecacatan terbesar dibandingkan dengan daerah disekitarnya sebesar 0,282 . Hal tersebut disebabkan terjadinya penurunan ketebalan apabila kedalaman dari proses drawing terlalu dalam menyebabkan kecacatan. 


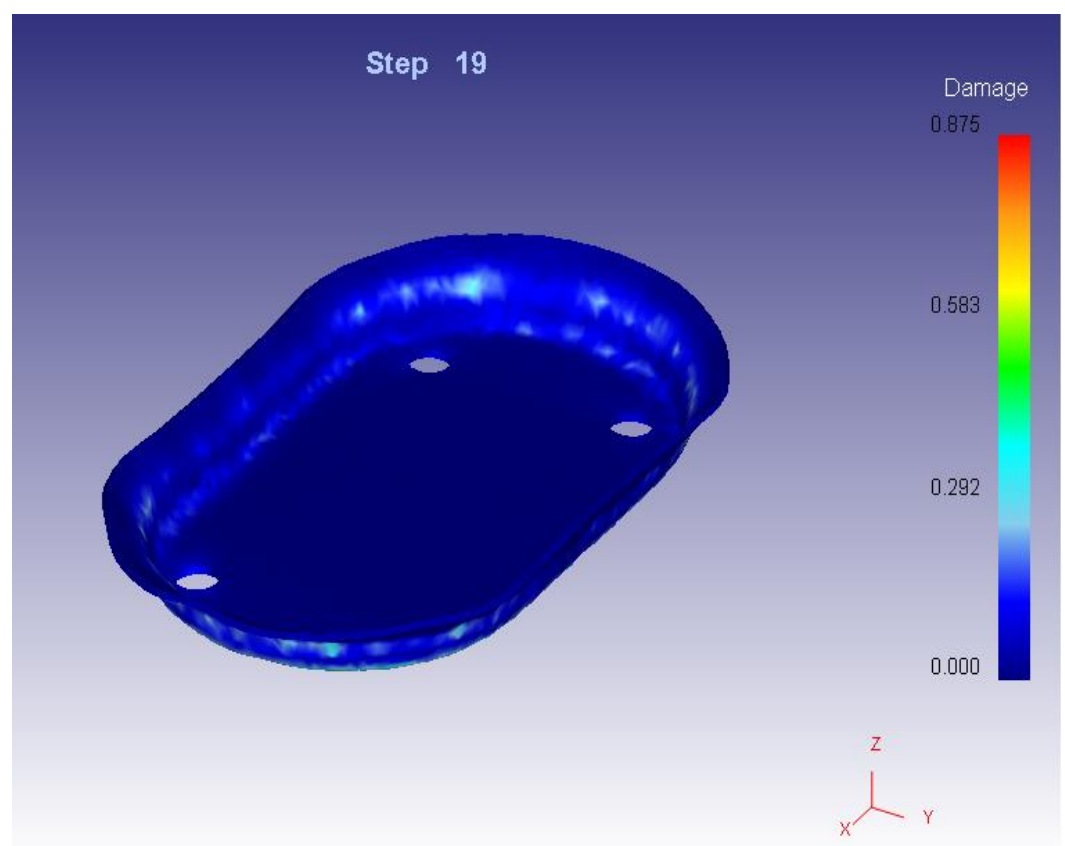

Gambar 11. Simulasi Damage Pedal Brake Pada Proses Drawing

\subsection{Simulasi Stress}

Simulasi stress benda kerja adalah simulasi untuk menampilkan kontur dan kurva stress terhadap waktu. Perubahan stress dapat dilihat pada Gambar 12 dimana stress benda kerja mengalami peningkatan yang curam sebesar sebesar $609 \mathrm{Mpa}$ dan stabil sampai mencapai langkah (stroke) terakhir yaitu 9,2 mm.
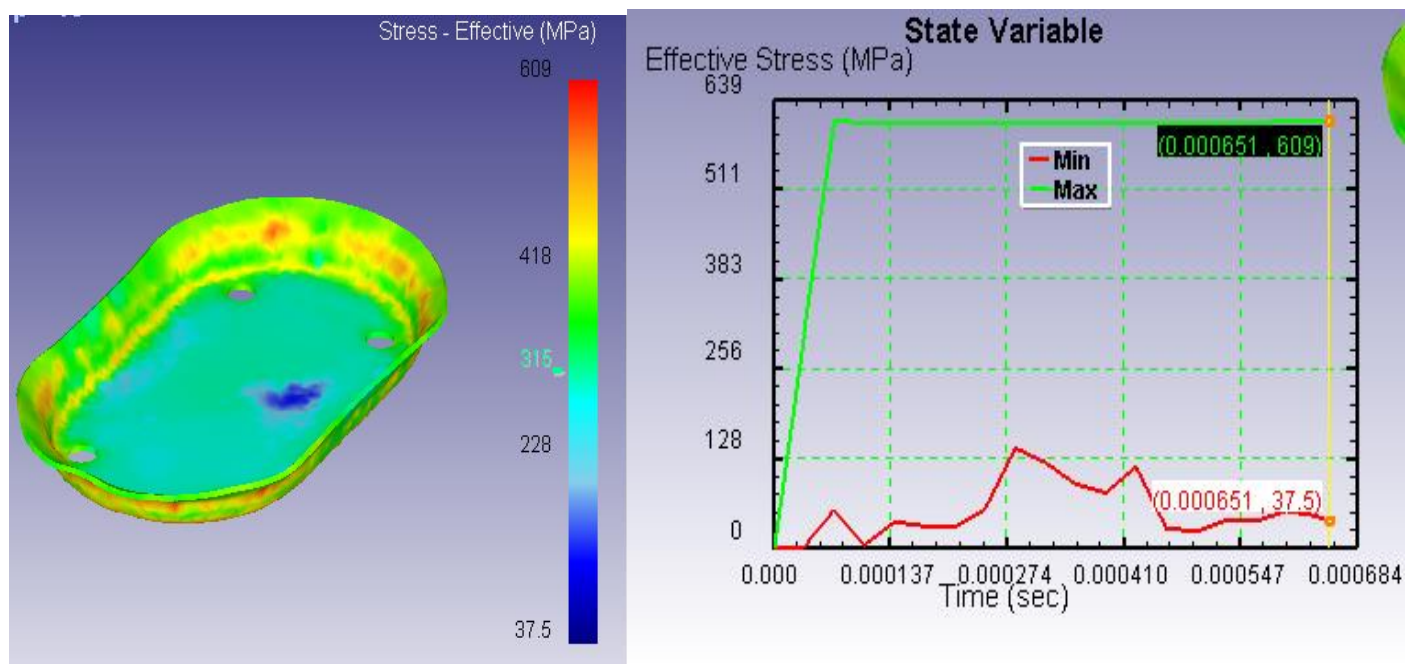

\section{Gambar 12. Simulasi Stress Pedal Brake Pada Proses Drawing}

\subsection{Perbandingan Hasil Perhitungan Analitis Dan Simulasi Software}

Hasil dari analisa perhitungan teori dibandingkan dengan menggunakan simulasi software untuk mengetahui apakah hasil tersebut dapat dibuktikan atau validasi. Adapun parameter yang dapat dibandingkan dari analisa dan simulasi yaitu gaya pembentukan maksimum dan kerja pembentukan, dapat dilihat pada Tabel 4 . 
Tabel 4. Perbandingan hasil perhitungan secara analitis dengan hasil simulasi software

\begin{tabular}{ccccc}
\hline No. & Parameter & $\begin{array}{c}\text { Perhitungan } \\
\text { Analitis }\end{array}$ & $\begin{array}{c}\text { Hasil } \\
\text { Simulasi }\end{array}$ & $\begin{array}{c}\text { Error } \\
(\%)\end{array}$ \\
\hline 1. & Gaya pembentukan maksimum $(k N)$ & 92,8 & 86,5 & $6 \%$ \\
2. & Kerja pembentukan $(k J)$ & 0,69 & 0,64 & $7 \%$ \\
\hline
\end{tabular}

Dari hasil perhitungan error dapat dikatakan bahwa hasil tersebut tidak berbeda jauh antara analisa teoritis dan simulasi software dan dapat dikatakan valid.

\section{KESIMPULAN}

Berdasarkan hasil analisis secara teoritis dan hasil simulasi software terhadap proses pembentukan pedal brake dengan menggunakan dies drawing pedal brake, dapat dihasilkan kesimpulan sebagai berikut:

a. Limiting Drawing Ratio adalah kemampuan suatu sheet metal untuk dilakukan deep drawing. Hasil perhitungan LDR sebesar 1,028 sedangkan data referensi untuk jenis cold-rolled LDR sebesar 2,8. Hal ini menjunjukkan bahwa kemampuan drawability untuk desain yang ada rendah, sehingga apabila dilakukan drawing lebih dalam, material akan rusak.

b. Rata-rata Plastic Strain Ratio $\left(\mathrm{R}_{\mathrm{avg}}\right.$ ) untuk jenis material yang dipakai benda kerja memiliki nilai $\mathrm{R}_{\text {avg }}$ sebesar 1,2 untuk jenis cold-rolled dimana angka tersebut cukup besar sehingga potensi terjadinya earing tidak terlalu besar.

c. Perbandingan gaya pembentukan secara teori dan simulasi memiliki error sebesar $7 \%$, sedangkan untuk kerja pembentukan memiliki error sebesar $6 \%$.

\section{DAFTAR PUSTAKA}

[1] Buku Pedoman PT. PINDAD (PERSERO). 1992. Bandung.

[2] Boljanovic, Vukota. 2004. Sheet Metal Forming Processes and Die Design. New York: Industrial Press Inc.

[3] Rashmi Dwivedia, Geeta Agnihotrib. 2017. Study of Deep Drawing Process Parameters. Materials Today: Proceedings 4:820-826

[4] DIN standard 8584: Fabricating process tensile - compressive forming.

[5] Sajjad Izadpanah, Seyed Hadi Ghaderi, Mahdi Gerdooei. 2016. Material parameters identification procedure for BBC2003 yield criterion and earing prediction in deep drawing. International Journal of Mechanical Sciences 115-116 : 552-563.

[6] Banabic D. 2010. Sheet metal forming processes. First Romania: Springer.

[7] Alexey Vishtal, Elias Retulainen. 2012. Deep-Drawing of Paper and Paperboard: The Role of Material Properties. Bio Resources. 7: 4424-4450.

[8] M. El Sherbiny an. El. 2014.Thinning and residual stresses of sheet metal in the deep drawing process. Materials and Design 55: 869-879.

[9] R.L. Whiteley. 1960. The Importance of directionality in drawing quality sheet steel. Trans. ASM 52: $154-164$.

[10] D.-K. Leu. 1997. Prediction of the limiting drawing ratio and the maximum drawing load in the cup drawing. International journal Mechanical Science. 37 (2) : 201-213.

[11] S. Kobayashi. 1989. Metal Forming and Finite element Methode. Oxford University Press. New York. pp.279-325

[12] Mikell P. Groover. 2010. Fundamentals Of Modern Manufacturing; Materials, Processes, and Systems 4th edition. John Wiley \& Sons, Inc. ISBN 978-0470-467002.

[13] Lange, K. 1985. Metal forming handbook. McGraw Hill. 
Jurnal SIMETRIS, Vol. 9 No. 1 April 2018

ISSN: 2252-4983

[14] Kalpakjian, Serope, Schimid, Steven R. 2009. Manufacturing Engineering and Technology Ed $6^{\text {th }}$ SI Units. Singapore: Prentice Hall 